\title{
Heavy metals in sediment profiles from Sepetiba and Ribeira Bays: A comparative study
}

\author{
F. de Carvalho Gomes ${ }^{1}$, J.M. Godoy ${ }^{2,3}$, M.L.D.P. Godoy², Z.L. de Carvalho², \\ R.T. Lopes ${ }^{1}$, J.-A. Sanchez-Cabeza ${ }^{4}$, L.D. de Lacerda ${ }^{5}$ and J.C. Wasserman ${ }^{6}$ \\ 1 Programa de Engenharia Nuclear, COPPE/UFRJ, Cidade Universitária, \\ Caixa Postal 68.509, 21945-970 Rio de Janeiro, Brazil \\ ${ }^{2}$ Instituto de Radioproteção e Dosimetria (IRD), Caixa Postal 37750, Barra da Tijuca, \\ 22642-970 Rio de Janeiro, Brazil \\ ${ }^{3}$ Departamento de Química, Pontifícia Universidade Católica do Rio de Janeiro (PUC-Rio), \\ Rua Marquês de São Vicente 225, 22453-900 Rio de Janeiro, Brazil \\ ${ }^{4}$ Marine Environment Laboratories Monaco, 4 Quai Antoine Premier, \\ MC98000 Monaco, Principality of Monaco \\ ${ }^{5}$ Laboratório de Ciências do Mar, Universidade Federal do Ceará, Fortaleza, Ceará \\ ${ }^{6}$ Dept. de Análise Geo-Ambiental, Instituto de Geociências - UFF, Niterói, RJ
}

\begin{abstract}
Three sediment cores were sampled at Sepetiba bay and four cores at Ribeira bay, Rio de Janeiro State, Brazil. Sedimentation rates were determined applying ${ }^{210} \mathrm{~Pb}$ dating. In the Ribeira Bay, the sedimentation rate increases in the direction from sampling point RB1 $\left(0.15 \mathrm{~cm} \mathrm{y}^{-1}\right)$, in the inner part of the bay, to $0.34 \mathrm{~cm} \mathrm{y}^{-1}$ in the sampling point RB4, close to its entrance. For the Sepetiba Bay, two sedimentation rates were observed: a lower rate of $0.3 \mathrm{~cm} \mathrm{y}^{-1}$, for the period before the 60 's, and a more recent rate of $0.75 \mathrm{~cm} \mathrm{y}^{-1}$. These findings agree with the construction of the Santa Cecília impoundment (1955) that brings water from the Paraíba do Sul Basin into the Guandu River, increasing its flow from the original $20 \mathrm{~m}^{3} \mathrm{~s}^{-1}$ to $160 \mathrm{~m}^{3} \mathrm{~s}^{-1}$. In order to determine the elemental concentrations, aliquot from the SB1 and RB4 cores were taken, totally dissolved and analyzed by ICP-MS. The hypothesis that Ribeira Bay could constitute a reference database for metal concentrations in the neighboring Sepetiba Bay is valid for several elements as $\mathrm{K}, \mathrm{Ti}, \mathrm{Mn}, \mathrm{Zn}, \mathrm{Ga}, \mathrm{Rb}, \mathrm{Sr}$ among others, but it isn't for other elements as $\mathrm{V}, \mathrm{Cr}$ and $\mathrm{Cd}$. Applying to the mean elemental concentration, of the upper contaminated $45 \mathrm{~cm}$ sediment layer, and to the elemental concentration of the deepest analyzed sediment layer a normalization to iron, a double ratio was calculated and it was concluded that the Sepetiba Bay sediments are, particularly, contaminated with Cr, may be, from a leather tanning plant existing in this region and $\mathrm{Cd}$ and $\mathrm{Zn}$ from the former Ingá Metais.
\end{abstract}

\section{INTRODUCTION}

Although Sepetiba and Ribeira Bays are only 40 kilometers apart, their physiographic and environmental constituents are considerably different. The former is a very flat environment, with high flux rivers that receive the wastes of over 400 industrial facilities. These waterways are contaminated with high levels of zinc and cadmium dumped from a large waste reservoir of a local metallurgical plant (Ingá Metais), which is presently being decommissioned [1-4]. Ribeira Bay, on the other hand, is a large cove of the Ilha Grande Bay, which is an important tourist resort of the Southern Rio de Janeiro State. Despite the presence of several condominiums, marinas, and the Almirante Alvaro Alberto Nuclear Power Plant effluent discharge point, it remains well preserved. Detailed site descriptions of Ribeira and Sepetiba Bays are available in the literature [1-8].

Cardoso et al. [1] have observed that, in Ribeira Bay, metals present in the superficial sediment were originated from natural sources, either associated with biogenic carbonates, or with ferromagnesian aluminum silicates, from marine- and continental-derived sources, respectively. 
In 2001, Pellegatti et al. [2] applied instrumental neutron activation analysis (INAA) to 28 superficial sediment samples in Sepetiba Bay, and subsequently built contour maps based on their results. Despite the general trend of higher concentrations at the northern portions of the coast where the main rivers and industrial effluent discharges are localized, only zinc was enriched relative to the mean shale. Due to the nuclear properties of their isotopes, it should be noted that INAA is not a suitable analytical technique for other important Sepetiba Bay contaminants as cadmium and lead [9].

Wasserman et al. [3] have sampled sediment cores at two locations in Sepetiba Bay. At each sampling location, two sediment cores were taken, one from the mangrove forest and the other from the tidal flat region at the edge of the mangrove forest (muddy flat). Three of the obtained sediment cores were well-defined, with higher concentrations at the top layers decreasing toward the bottom layers. Based on the local industrial development history, a sedimentation rate of $0.8 \mathrm{~cm} \mathrm{y}^{-1}$ was estimated, but it should be interpreted cautiously, as no ${ }^{210} \mathrm{~Pb}$ dating was performed.

Like Wasserman et al. [3], Marques Jr. et al. [4] have taken sediment cores from the tidal flat region at the edge of the mangrove forest. ${ }^{210} \mathrm{~Pb}$ dating, zinc and cadmium concentrations, and stable lead isotope compositions were determined. A $7.5 \mathrm{~cm}$ mixing zone and two sedimentation rates were observed, one at the top, at $1.0 \mathrm{~cm} \mathrm{y}^{-1}$, and another at the bottom, at $0.8 \mathrm{~cm} \mathrm{y}^{-1}$. Both zinc and cadmium concentration age profiles were consistent with the historical industrial phases, and the pre-industrial levels were estimated to be $70-100 \mathrm{mg} \mathrm{kg}^{-1}$ for zinc and $<0.2 \mathrm{mg} \mathrm{kg}^{-1}$ for cadmium.

Herein, it is compared the changes in the overall metal profiles over the past century examining elemental concentrations in the bottom sediments of Ribeira and Sepetiba Bay. These comparisons were made to verify whether Ribeira Bay could constitute a reference database for metal concentrations in the neighboring Sepetiba Bay, as proposed by Cardoso et al. [1]. It also aims to verify if the changes in the concentration of elements such as aluminum, iron and rare-earth reflect man-made interventions in the Sepetiba Bay drainage system [6]. Due to the actual harbors construction and expansion in Sepetiba Bay, large areas have been dredged and, in order to support the necessary environmental impact assessment studies, metal fluxes and burden will be also presented. Based on the metal profiles, it will be investigated which metals, further than $\mathrm{Zn}$ and $\mathrm{Cd}$, are present in Sepetiba Bay sediments as a contaminant.

\section{MATERIALS AND METHODS}

Three sediment cores were sampled at Sepetiba Bay, and four cores were sampled at Ribeira Bay, as shown in Figure 1. Ribeira Bay cores were taken with a gravity corer and immediately sliced into $3 \mathrm{~cm}$ layers, while Sepetiba Bay cores were hand-collected with PVC tubes and also immediately sliced into $3 \mathrm{~cm}$ layers. The bottom sediments at sampling points RB1 and RB2 were quite compact yielding sediment cores shorter than those obtained at sampling points RB3 and RB4. The slices were lyophilized and homogenized using an agate mortar. 3 gram aliquots were taken for ${ }^{210} \mathrm{~Pb}$ determination following the procedure described by Godoy et al. [10].

Two hundred and fifty milligram aliquots were taken and totally digested with an acid mixture $\left(0.4 \mathrm{~mL} \mathrm{HClO}_{4}+10 \mathrm{~mL} \mathrm{HNO}_{3}+2 \mathrm{~mL} \mathrm{HF}\right)$ in a Teflon digestion vessel, heated to dryness and the residues were re-dissolved in $40 \mathrm{~mL} 2 \% \mathrm{HNO}_{3}$. After a $1: 10$ dilution with $2 \% \mathrm{HNO}_{3}$, the elemental concentrations were determined by ICP-MS (Perkin-Elmer ELAN 6000) as described by Godoy et al. [11]. Blank and reference sample (NIST-SRM-2709 San Joaquin soil sample) were included in every sample batch.

\section{RESULTS AND DISCUSSION}

The variations in ${ }^{210} \mathrm{~Pb}$ concentrations within the sediment cores from Ribeira Bay are shown in Figure 2a-d. If Ribeira bay is indeed well preserved, the Constant Initial Concentration model (CIC) should be valid, and an exponential variation in ${ }^{210} \mathrm{~Pb}$ concentration with depth should be observed. 
Despite a superficial mixing zone in cores 1, 2 and 3, this exponential behavior can be observed in all four cores. The mixing zone is most intense for point 1 , obtained from the inner part of the bay, and tends to disappear toward point 4 , close to its entrance. The sedimentation rate seems to increase in the same direction, from $0.15 \mathrm{~cm} \mathrm{y}^{-1}$ at the sampling point $\mathrm{RB} 1$, to $0.34 \mathrm{~cm} \mathrm{y}^{-1}$ in the sampling point RB4. Since no significant river discharge to Ribeira Bay exists, the main sediment source appears to be the water coming from Ilha Grande Bay during high tides. Therefore, a gradient is observed from the entrance to the inner part of the bay. This gradient explains also why more compact bottom sediments are observed at sampling points RB1 and RB2 than at sampling points RB3 and RB4.

Bracuy Cove is an inlet that belongs to Ribeira Bay (Figure 1). The sampling point RB4 is inside Bracuy Cove, in a region with a sedimentation rate of $0.3 \mathrm{~cm} \mathrm{y}^{-1}$ according to Barbosa [12]. As such, the obtained value of $0.34 \mathrm{~cm} \mathrm{y}^{-1}$ agrees well with this previous work.

In Sepetiba Bay, several man-made interventions on the drainage basin and in the bay itself, including harbors, construction and dredging, render a CIC model unusable, even more, fully mixed and useless cores can be also obtained. The ${ }^{210} \mathrm{~Pb}$ variation within the sediment layers for the cores taken from Sepetiba bay are shown in Figure $3 \mathrm{a}-\mathrm{c}$.

At sampling point 1 (Figure 3a), a mixing layer of $20 \mathrm{~cm}$ was observed, and a negative ${ }^{210} \mathrm{~Pb}$ exponential decay with this depth was identified. The first layer below this $20 \mathrm{~cm}$ depth presents an anomalous ${ }^{210} \mathrm{~Pb}$ concentration, which also has a distinct chemical composition from its neighboring layers. It represents an outer limit for the mixing layers, and can likely be correlated with some event that happened back in the past.

Two different Constant of Rate Supply (CRS) approaches, and one CIC approach were tested. For the first, no changes were applied to the CRS model. For the second CRS model, the mixing layer was considered, and a modified CRS equation was applied as proposed by Appleby and Oldfield [13], assigning 11 years old to the $20 \mathrm{~cm}$ sediment depth. This age was chosen because the differences in chemical composition observed at the $20 \mathrm{~cm}$ sediment depth; it was supposed that it exists due to the Ingá Metais waste dam breakage occurred in 1996.

The difference between the two CRS models is approximately 2 years and nearly constant. On the other hand, the difference between the second CRS model and the CIC results are much higher. One way to validate these models is to use information from the well-documented industrial development of Sepetiba Bay, particularly that related to the zinc and cadmium profiles in this sediment core. Zinc and cadmium profiles at various sediments depths are typical of a contaminated area with lower concentrations near the bottom, higher concentrations near the top, and a transition zone in the middle, in contrast with the same profile for Ribeira Bay, where $\mathrm{Zn}$ and $\mathrm{Cd}$ are quite constant with the depth ( $\mathrm{Zn}$ : bottom $=99 \mathrm{mg} \mathrm{kg}^{-1}$ and top $=106 \mathrm{mg} \mathrm{kg}^{-1}$; $\mathrm{Cd}$ : bottom $=0.20 \mathrm{mg} \mathrm{kg}^{-1}$ and top $=0.25 \mathrm{mg} \mathrm{kg}^{-1}$ ). The zinc concentration in the deepest layer $\left(54 \mathrm{mg} \mathrm{kg}^{-1}\right)$ is lower than the average crustal concentration proposed by Wedepohl [14] (100 $\left.\mathrm{mg} \mathrm{kg}^{-1}\right)$, and the mean zinc concentration in Ribeira Bay sediments. However, it is similar to the zinc baseline value proposed for Sepetiba Bay by a number of authors [2-6]. In contrast, the cadmium concentration in the deepest layer $\left(0.34 \mathrm{mg} \mathrm{kg}^{-1}\right)$ is higher than the average crustal concentration proposed by Wedepohl [14] $\left(0.10 \mathrm{mg} \mathrm{kg}^{-1}\right)$, however, falls is in the range of values observed in Ribeira Bay (mean $=0.21$ and range 0.32-0.14 $\mathrm{mg} \mathrm{kg}^{-1}$ ) [1]. Cadmium in Sepetiba Bay sediment is less studied than zinc, and only one reference to a baseline concentration appears in the literature $\left(<0.2 \mathrm{mg} \mathrm{kg}^{-1}\right)$ [4].

Figure 4, based on the second CRS model, takes into account the initial mixing layer and, therefore, can indicate only the ages corresponding to the beginning and to the end of this layer. Since there is a transition zone between the non-contaminated bottom layers and the contaminated upper layers, it was not possible to identify the exact beginning of either zinc or cadmium contamination, and it was thus not possible to correlate this with the construction and operation of the local zinc metallurgic plant (Ingá Metais, Figure 1) in 1958. However, it is possible to verify that zinc and cadmium concentrations reached a higher level after 1960 (46 cm sediment layer), in agreement with the observations of Lacerda and Molisani [15]. Figure 4 indicates also that even after the closure of the zinc plant (1997) [15], zinc 


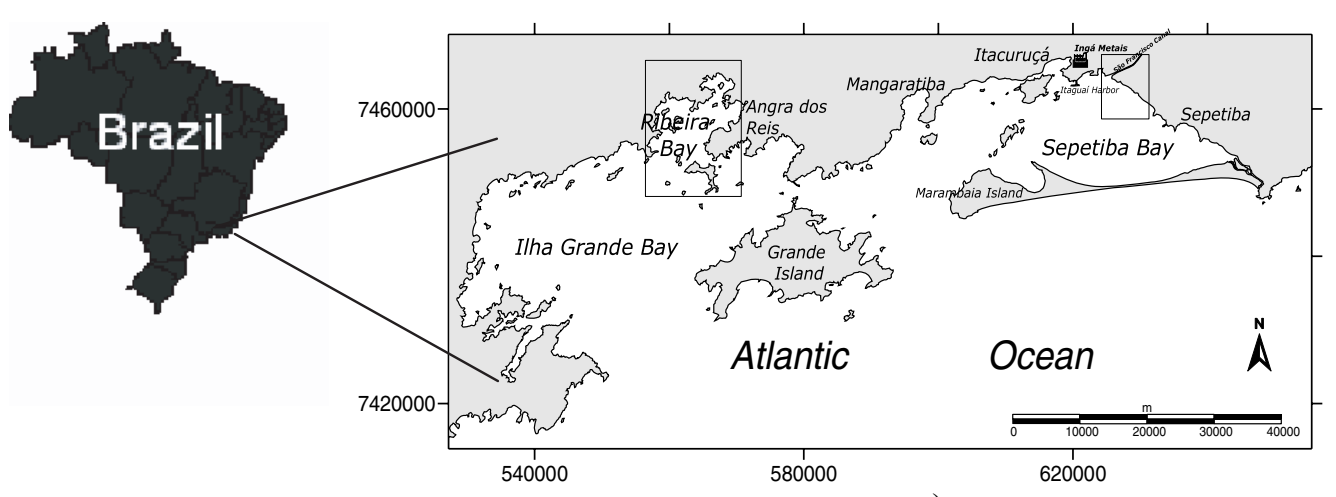

a)

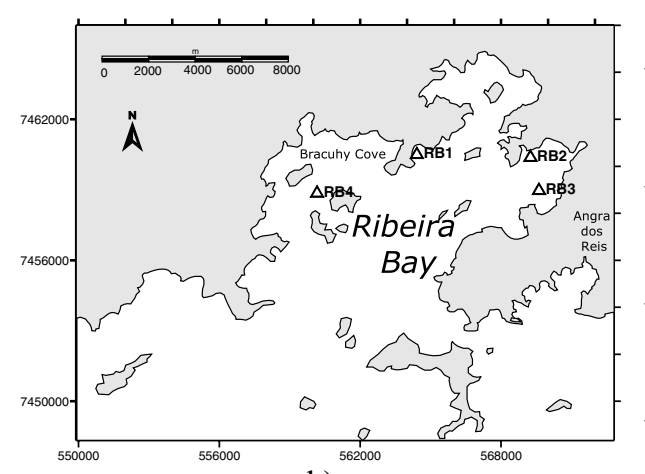

b)

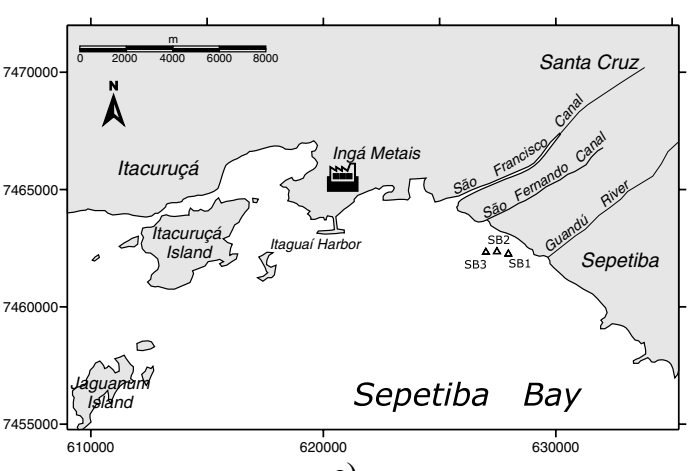

c)

Figure 1. Sepetiba and Ilha Grande Bays system (a). Squares indicate the locations in Ribeira Bay and Sepetiba where samples were collected (see detailed maps b and c). Sediment profile sampling stations in Ribeira Bay (b) and Sediment profile sampling stations in Sepetiba Bay (c).

and cadmium anthropogenic sources to Sepetiba Bay remained elevated, likely due to new industrial facilities and growing urban waste production.

Based on core SB1, two sedimentation rates were observed: a lower rate of $0.3 \mathrm{~cm} \mathrm{y}^{-1}$ for the period before the 1960s, and a more recent rate of $0.75 \mathrm{~cm} \mathrm{y}^{-1}$. These findings correlate with construction of the Santa Cecília impoundment in 1955, which brings water from the Paraíba do Sul Basin into the Guandu River, and increases the river flow from $20 \mathrm{~m}^{3} \mathrm{~s}^{-1}$ to $160 \mathrm{~m}^{3} \mathrm{~s}^{-1}$. According to Molisani et al. [16], this represents at least $30 \%$ of the total suspended matter entering the bay, and has doubled the mass sedimentation rate in the Northeastern shore of Sepetiba Bay over the past 50 years. A much deeper mixing layer was observed in the core SB2, at about $50 \mathrm{~cm}$. Since only three samples below this mixing layer were available, a rough estimate of the sedimentation rate could be carried out applying the CIC model. The calculated value was $0.75 \mathrm{~cm} \mathrm{y}^{-1}$, which is consistent with values presented by Wasserman et al. [3] and Marques Jr. et al. [4] and with the core SB1. The ${ }^{210} \mathrm{~Pb}$ fluxes were calculated in both cores SB1 and SB2. In order to obtain the total ${ }^{210} \mathrm{~Pb}$ inventory for core SB2, the missing excess ${ }^{210} \mathrm{~Pb}$ concentration corresponding to the sediment layers below the available samples were calculated based on the CIC model. The obtained ${ }^{210} \mathrm{~Pb}$ fluxes were $49 \mathrm{mBq} \mathrm{cm}^{-2} \mathrm{y}^{-1}$ and $54 \mathrm{mBq} \mathrm{cm}^{-2} \mathrm{y}^{-1}$ for cores SB1 and SB2, respectively. Since these values were similar and within the range presented in the literature [13], an additional level of confidence is conferred upon the obtained ${ }^{210} \mathrm{~Pb}$ results. The ${ }^{210} \mathrm{~Pb}$ flux calculated based on Ribeira Bay core RB4 is significantly smaller than those of Sepetiba Bay, with 


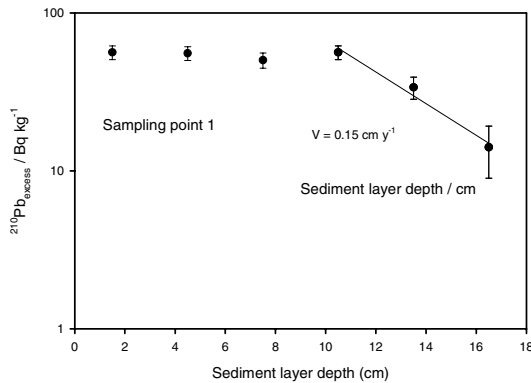

a)

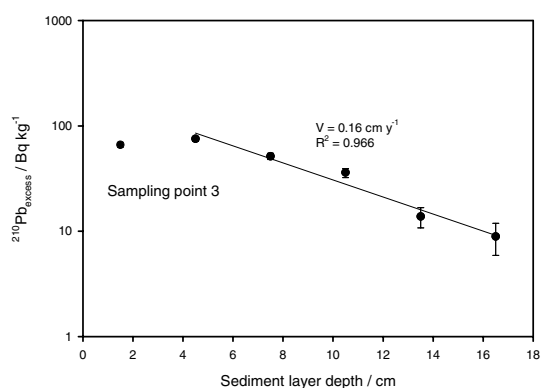

c)

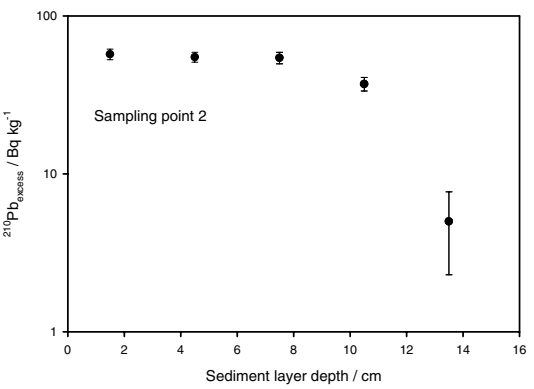

b)

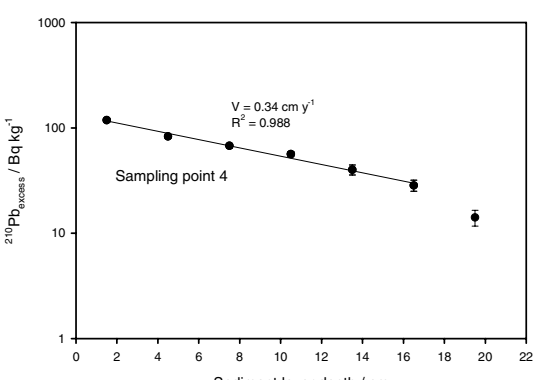

d)

Figure 2. Excess ${ }^{210} \mathrm{~Pb}$ profiles with the sediment layer depth for Ribeira Bay sampling points 1-4.

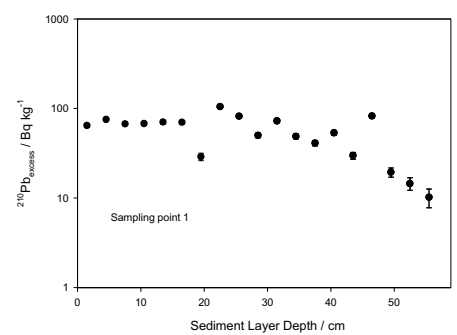

a)

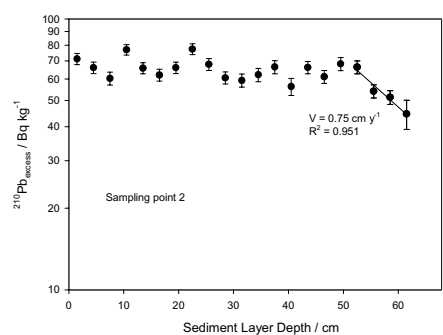

b)

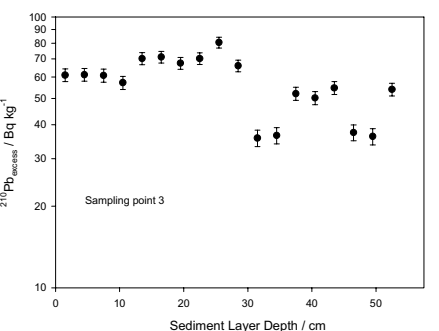

c)

Figure 3. Excess ${ }^{210} \mathrm{~Pb}$ profiles with the sediment layer depth for Sepetiba Bay sampling points 1-3.

a flux value of $38 \mathrm{mBq} \mathrm{cm}^{-2} \mathrm{y}^{-1}$. The higher values of Sepetiba Bay are attributed to the presence of an additional sediment supply originating from the nearby São Francisco and São Fernando channels, and from the Guandu River (Figure 1). The calculated Ribeira Bay ${ }^{210} \mathrm{~Pb}$ flux agrees with the average value, of $37 \mathrm{mBq} \mathrm{cm}^{-2} \mathrm{y}^{-1}$ obtained based on the results of three sediment cores analyzed by Barbosa [12] and sampled at Bracuy Cove (Figure 1). The variation in ${ }^{210} \mathrm{~Pb}$ concentration with depth for core SB3 shows a highly unconventional profile and thus no further attempt to calculate the ${ }^{210} \mathrm{~Pb}$ ages was performed.

Metal concentrations were evaluated in both the RB4 and SB1 sediment cores, corresponding directly to those with the better ${ }^{210} \mathrm{~Pb}$ profiles. These results were applied to validate the Cardoso's hypothesis that Ribeira Bay could constitute a reference database for metal concentrations in the neighboring Sepetiba Bay, the mean elemental concentration of the core RB4 was plotted against the elemental concentration in the deepest layer of the core SB1, taken as the background level (Figure 5). It can be seem that this hypothesis is valid for several elements as $\mathrm{K}$, Ti, Mn, $\mathrm{Zn}, \mathrm{Ga}, \mathrm{Rb}, \mathrm{Sr}$ among others, but it isn't for other elements as $\mathrm{V}, \mathrm{Cr}$ and $\mathrm{Cd}$. 


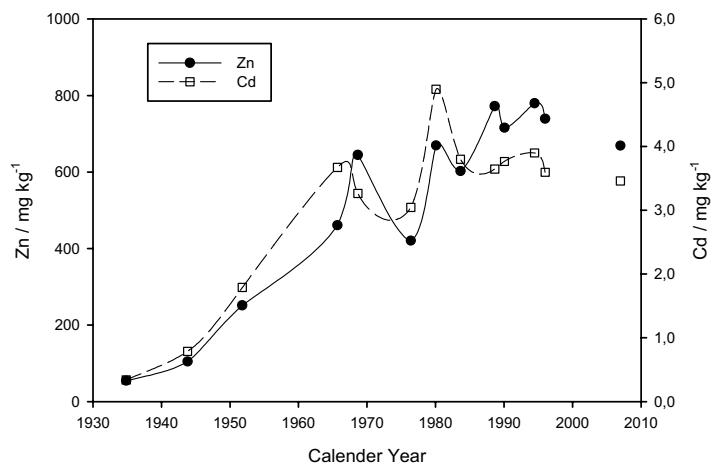

Figure 4. Zinc and cadmium concentration profile with the sediment layer age at Sepetiba Bay sampling point 1.

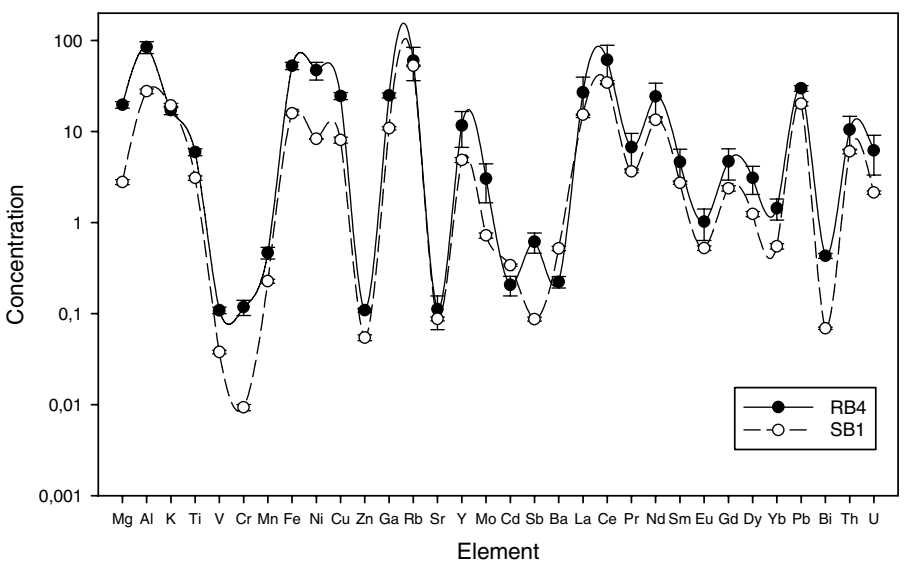

Figure 5. Mean elemental concentration for the core RB4 and the bottom layer of the core SB1. Values in $\mathrm{g} \mathrm{kg}^{-1}$ for $\mathrm{Mg}, \mathrm{Al}, \mathrm{K}, \mathrm{Ti}, \mathrm{V}, \mathrm{Cr}, \mathrm{Mn}, \mathrm{Fe}, \mathrm{Zn}, \mathrm{Sr}$ and $\mathrm{Ba}$, for the others the values are in $\mathrm{mg} \mathrm{kg}^{-1}$.

Another approach was tested for the heavy metals in the Sepetiba Bay samples: considering the upper $45 \mathrm{~cm}$ sediment layer as contaminated, a mean value for each element was calculated. This mean value was normalized by the mean iron concentration and the same normalization procedure was carried out for the results of the deepest layer, taken as non-contaminated. The iron normalized ratios for the upper layer were divided by the corresponding normalized values of the bottom layer and, when the result of this double ratio was higher than one then this upper $45 \mathrm{~cm}$ layer was taken as contaminated with this element. This was the case for only for six elements: $\mathrm{Sb}$ (1.16), Cu (1.38), Bi (1.69), Cr (2.51), $\mathrm{Cd}$ (3.38) and Zn (3.76). It means that the Sepetiba Bay major contaminants are Cd and Zn from the former Ingá Metais and $\mathrm{Cr}$, probably, from a leather tanning facility existing in this area.

The Fe/Al ratio throughout the Ribeira Bay profile is constant, and the mean value of 0.63 is similar to the value calculated for the continental crust based on the work of Wedepohl (0.54) [14]. A similar result is also obtained for Sepetiba Bay with episodic changes. The more recent peaks, with a higher $\mathrm{Fe} / \mathrm{Al}$ ratio, may be correlated with some event related to the large steel industry (Cosigua) existing in the Sepetiba Bay region. The Ti/Fe ratio profiles in both sediment cores (SB1 and RB4) are similar to the Fe/Al profiles. However, unlike the Fe/Al profiles, the Ti/Fe profiles indicate the existence of two end-members, one at the bottom and one actual, starting after the depth corresponding to the period of construction of the Santa Cecília impoundment in 1955. It was observed a peak in both $\mathrm{Fe} / \mathrm{Al}$ and $\mathrm{Ti} / \mathrm{Fe}$ ratios for the Ribeira Bay sediments at $7.5 \mathrm{~cm}$, corresponding to the year 1985 applying a sedimentation 
rate of $0.34 \mathrm{~cm} \mathrm{y}^{-1}$. On February 27, 1985, a large amount of soil slid down from the hills in front of Piraquara de Fora Cove, destroying the road and the Nuclear Power Plant environmental monitoring laboratory. This event served to validate the application of the CIC method in this sediment core.

\section{CONCLUSIONS}

The present work evaluated present and previous inputs of metals to Sepetiba and Ribeira Bays. The data indicate that although both systems are connected to some extent, very little transfer of contamination between the two is recorded over the past 100 years.

The Cardoso's hypothesis, that Ribeira Bay could constitute a reference database for metal concentrations in the neighboring Sepetiba Bay, is valid for several elements as $\mathrm{K}, \mathrm{Ti}, \mathrm{Mn}, \mathrm{Zn}, \mathrm{Ga}$, $\mathrm{Rb}, \mathrm{Sr}$ among others, but it isn't for other elements as $\mathrm{V}, \mathrm{Cr}$ and $\mathrm{Cd}$.

The ${ }^{210} \mathrm{~Pb}$-dating tool proved its efficacy in determining a very precise temporal record of sediment contamination, allowing for the direct identification of the impact of historical events. In Ribeira Bay, the sedimentation rate increases in the direction from sampling point RB1 $\left(0.15 \mathrm{~cm} \mathrm{y}^{-1}\right)$, in the inner part of the bay, to $0.34 \mathrm{~cm} \mathrm{y}^{-1}$ in the sampling point RB4, close to its entrance. For the Sepetiba Bay, two sedimentation rates were observed: a lower rate of $0.3 \mathrm{~cm} \mathrm{y}^{-1}$, for the period before the 1960's, and a more recent rate of $0.75 \mathrm{~cm} \mathrm{y}^{-1}$. These findings correlate with construction of the Santa Cecília impoundment in 1955, which brings water from the Paraíba do Sul Basin into the Guandu River, and increases the river flow from $20 \mathrm{~m}^{3} \mathrm{~s}^{-1}$ to $160 \mathrm{~m}^{3} \mathrm{~s}^{-1}$.

\section{Acknowledgments}

This work was partly supported by Ecologus Environmental Engineering, within the scope of a contract for an Environmental Impact Assessment of the Sepetiba Bay, and by the Conselho Nacional de Desenvolvimento Científico e Tecnológico (CNPq). The IAEA is grateful for the support provided to its Marine Environment Laboratory by the Government of the Principality of Monaco.

\section{References}

[1] Cardoso, A.G.A., Boaventura, G.R., Silva-Filho, E.V. and Brod, J.A., J. Braz. Chem. Soc. 6 (2001) 767-774.

[2] Pellegati, F., Figueiredo, A.M.G. and Wasserman, J.C., Geostand. Newsl. 25 (2001) 307-315.

[3] Wasserman, J.C., Figueiredo, A.M.G., Pellegati, F. and Silva-Filho, E.V., J. Geochem. Explor. 72 (2001) 129-146.

[4] Marques Jr., A.N., Monna, F., Silva-Filho, E.M., Fernex, F.E. and Simões Filho, F.F.L., Mar. Pollut. Bul. 52 (2006) 532-539.

[5] Magalhães, V.F., Carvalho, C.E.V. and Pfeiffer, W.C., Water, Air, Soil Pollut. 129 (2001) 83-90.

[6] Barcellos, C., Lacerda, L.D. and Ceradini, Environ. Geol. 32 (1997) 203-209.

[7] Leal Neto, A.C., Legey, L.F.L., González-Araya, M.C. and Jablonski, S., Environ. Manage. 38 (2006) 879-888.

[8] Cunha, C.L.N., Rossman, P.C.C., Ferreira, A.P. and Monteiro, T.C.N., Cont. Shelf Res. 26 (2006) 1940-1953.

[9] Godoy, J.M., In Manual of Physico-Chemical Analysis of Aquatic Sediments, Mudroch A., Azcue, J.M., Mudroch P. eds., CRC Lewis Publishers, 1997, p. 147-174.

[10] Godoy, J.M., Moreira, I., Wanderley, W., Simões Filho, F.F.L. and Mozeto, A.A., Radiat. Prot. Dos. 75 (1998) 111-115.

[11] Godoy, M.L.D.P., Godoy, J.M., Roldão, L.A. and Conti, L.F.C., J. Braz. Chem. Soc. 15 (2004) $122-130$. 
[12] Appleby, P.G. and Oldfield, F. In Uranium-series Disequilibrium - Application to Earth, Marine and Environmental Sciences $2^{\text {nd }}$ edition, Ivanovich, M., Harmon, R.S., eds.; Oxford Sciences Publ., 1992, p. 731.

[13] Barbosa, A.A., Doctor Thesis, Departamento de Geoquímica, Universidade Federal Fluminense, Brazil, 2001, 114 pages.

[14] Wedepohl, K.H., Geochim. Cosmochim. Acta 59 (1995) 1217-1232.

[15] Lacerda, L.D. and Molisani, M.M., Mar. Pollut. Bul. 52 (2006) 969-987.

[16] Molisani, M.M., Marins, R.V., Machado, W., Paraquetti, H.H.M., Bidone, E.D. and Lacerda, L.D., Reg. Environ. Change 4 (2004) 17-27. 